\title{
PACMHCI V5 CSCW1 April 2021 Editorial
}

SHAOWEN BARDZELL, Pennsylvania State University, USA

JUHO KIM, KAIST, South Korea

SIÂN LINDLEY, Microsoft Research, UK

ALEKSANDRA SARCEVIC, Drexel University, USA

SARITA SCHOENEBECK, University of Michigan, USA

\section{CCS Concepts: • Human-centered computing $\rightarrow$ Collaborative and social computing; $\bullet$ Information systems $\rightarrow$ Collaborative and social computing systems and tools}

\section{ACM Reference format:}

Shaowen Bardzell, Juho Kim, Siân Lindley, Aleksandra Sarcevic and Sarita Schoenebeck. 2021. PACMHCI V5 CSCW1 April 2021 Editorial. In Proceedings of the ACM on Human-Computer Interaction, Vol. 5, CSCW1, Article 1 (April 2021), 1 page, https://doi.org/10.1145/3449254

We are delighted to present this issue of the Proceedings of the ACM on Human-Computer Interaction, which contains scholarship from the Computer-Supported Cooperative Work and Social Computing (CSCW) community. This issue has 190 papers, 177 submitted in June 2020 and 13 submitted in October 2020. It represents contributions from two Program Committees, including external reviewers, Associate Chairs, and Editors, who together have conducted a rigorous review process. As Papers Chairs, we are grateful for the community's collective efforts to continue shaping and sharing CSCW's tradition of high-quality scholarship during a global pandemic.

\footnotetext{
Author's addresses: Shaowen Bardzell, sbardzell@psu.edu, Pennsylvania State University, USA; Juho Kim, juhokim@kaist.ac.kr, KAIST, South Korea; Siân Lindley, sianl@microsoft.com, Microsoft Research, UK; Aleksandra Sarcevic, as3653@drexel.edu, Drexel University, USA; Sarita Schoenebeck, yardi@umich.edu, University of Michigan, USA.

Permission to make digital or hard copies of part or all of this work for personal or classroom use is granted without fee provided that copies are not made or distributed for profit or commercial advantage and that copies bear this notice and the full citation on the first page. Copyrights for third-party components of this work must be honored. For all other uses, contact the owner/author(s).

(c) Copyright is held by the Owner/Author(s)

2573-0142/2021/04 - Art1

https://doi.org/10.1145/3449254
}

PACM on Human-Computer Interaction, Vol. 5, No. CSCW1, Article 1, Publication date: April 2021. 